\title{
Variation in Organic Acids Content during Ripening of Pickled White Cheese
}

\author{
A. S. Akalin, ${ }^{\star}$ S. Gönç, ${ }^{\star}$ and Y. Akbaş† \\ *Department of Dairy Technology, \\ †Department of Animal Science, Biometry and Genetics Unit \\ Faculty of Agriculture, \\ University of Aegean, Bornova-Izmir 35100, Turkey
}

\begin{abstract}
Nine organic acids (formic, pyruvic, lactic, acetic, orotic, citric, uric, propionic, and butyric) were analyzed during ripening of pickled White cheese for 12 mo by high-performance liquid chromatography with a reverse phase $\mathrm{C} 18(120 \times 5-\mathrm{mm})$ column and UV detector. The level of total organic acids showed an increase along the ripening period, but its composition varied during the process. Initially, lactic acid accounted for $95 \%$ of the total, after 9 and 12 mo of ripening, butyric acid constituted 20 and $27 \%$ of the total, respectively. Each organic acid presented a characteristic pattern of change during ripening. Discriminant analysis classified cheeses according to their age. Stepwise regression analysis allowed estimation of the ripening time of samples according to their organic acid levels.
\end{abstract}

(Key words: organic acid, pickled White cheese)

\section{INTRODUCTION}

Cheese ripening is characterized by a series of complex physical, chemical, and microbiological changes affecting the principal components of the cheese. Extensive research has been directed at finding and evaluating microbiological and biochemical parameters by which cheese could be classified and whereby uniform cheese quality could be established (Adda et al., 1982; Farkye and Fox, 1990; Seitz, 1990). Attention has been given to the mechanisms by which cheese curds become distinctively flavored cheeses, but maturation processes are not well understood for most cheeses due to the heterogeneous nature of the product. Numerous active microbial enzymes are present together with the metabolites; the changes in ripening depend on the biochemical conditions of curd, i.e., water activity, $\mathrm{pH}$, oxidationreduction potential, mineral contents, and several other factors including ripening temperature, level and

Received April 30, 2001.

Accepted February 5, 2002.

Corresponding author: S. Akalin; e-mail: sakalin21@yahoo.com. method of salt addition, and the nature of secondary microflora (Law, 1984).

The acceptability of cheese depends largely on the flavor formed during ripening. The flavor profiles of cheeses are complex and are variety- or type-specific. These profiles are influenced by many substances, e.g., organic acids, sulphur compounds, lactones, methyl ketones and alcohols, and phenolic substances (Seitz, 1990; Urbach, 1993). The organic acids, important flavor substances of most aged cheeses, form as a result of the hydrolysis of fatty acids, normal bovine metabolic processes, and bacterial growth, or appear by addition of acidulants during cheesemaking (Adda et al., 1982). Quantitative determination of organic acids is important to flavor studies for nutritional reasons and as an indicator of bacterial activity. Hough et al. (1996), working on Reggianito grating cheese showed that total aroma intensity was correlated with organic acid concentrations.

Attempts to use HPLC profiles as the classification parameter of maturity in cheese varieties have been reported by Pham and Nakai (1983) and Mohler Smith and Nakai (1990). With the use of HPLC, a number of authors have attempted to use organic acid content as an indicator of microbial metabolism and classification parameter of various cheese types for their age (Marsili, 1985; Panari, 1986; Bevilacqua and Califano, 1989; Lombardi et al., 1994; Lues and Botha, 1998; Califano and Bevilacqua, 1999).

Pickled White cheese is the most important cheese variety manufactured in Turkey. Due to economic and consumer preference reasons, this cheese and its manufacture have evolved somewhat differently among producers in Turkey. Major research and process improvement efforts have been carried out to ensure standard quality. Generally, the cheese is stored at 4 to $5^{\circ} \mathrm{C}$ for 3 mo. The aging period can be extended to 12 mo depending on the raw milk quality, processing methods of cheesemaking, ripening temperature, etc., in order to form excellent flavor in cheese. The sensory properties of pickled White cheese vary widely. In particular, organic acids contribute to the flavor of most aged cheeses, including pickled White cheese. 
Table 1. Retention time $\left(t_{r}\right)$, coefficients of determination $\left(R^{2}\right)$ for the standard curves, and recovery $(\%)$ for organic acids.

\begin{tabular}{llll}
\hline Constituent & $\begin{array}{l}\mathrm{T}_{\mathrm{r}} \\
(\mathrm{min})\end{array}$ & $\mathrm{R}^{2}$ & $\begin{array}{l}\text { Recovery } \\
(\%)\end{array}$ \\
\hline Formic & 4.52 & 0.9998 & 89.5 \\
Pyruvic & 5.02 & 0.9997 & 90.2 \\
Lactic & 6.05 & 0.9999 & 98.7 \\
Acetic & 8.05 & 0.9988 & 90.4 \\
Orotic & 9.26 & 0.9982 & 94.9 \\
Citric & 9.80 & 0.9999 & 86.3 \\
Uric & 13.57 & 0.9999 & 92.7 \\
Propionic & 16.12 & 0.9988 & 96.5 \\
Butyric & 23.58 & 0.9999 & 91.9 \\
\hline
\end{tabular}

The aims of this study were 1) to investigate the changes in organic acids content (formic, pyruvic, orotic, uric, lactic, acetic, citric, propionic, and butyric) by reverse-phase, HPLC during pickled White cheese aging; and 2) to evaluate the contribution of organic acids to maturity of the pickled White cheese. For this purpose, discriminant analysis was applied to our HPLC data to investigate whether classification of pickled White cheeses according to their ripening time could be done solely on the organic acids. Several authors have used the discriminant analysis successfully for classification of maturity of Cheddar (Pham and Nakai, 1983), frozen Cabrales (Alonso et al., 1987), Port Salut Argentino (Bevilacqua and Califano, 1992), Reggianito (Lombardi et al., 1994), and low-moisture Mozzarella (Califano and Bevilacqua, 1999) cheeses.

\section{MATERIALS AND METHODS}

\section{Cheese Making}

Twenty-one cheeses were produced at a local dairy plant (Can Dairy Products Plant, Torbali, Izmir, Turkey) according to the following procedure: Pasteurized milk (2.6\% milk fat) was cooled to $38^{\circ} \mathrm{C}$ and pumped into a cheese vat. Cheese starter DVS R-703 (Chr. Hansen Laboratorium, Denmark) was added at the rate of $0.002 \%$ along with $0.2 \% \mathrm{CaCl}_{2}$ and $0.015 \%$ calf rennet CLB 1000K016 (DSM, Delft, Netherlands). Cheeses were produced in one batch to minimize variability between cheese samples.

The starter consisted of Lacococcus lactis ssp. cremoris and Lactococcus lactis ssp. lactis in equal rates. Also, $0.01 \%$ liquid yogurt starter culture was added (Aegean Univ., Faculty of Agric., Dept. of Dairy Technol., Izmir, Turkey), containing Streptococcus salivarius ssp. thermophilus and Lactobacillus delbrueckii ssp. bulgaricus in equal rates.

When the curd was sufficiently firm ( $45 \mathrm{~min})$, it was cut. Afterwards, the curd was molded, and the whey was drained by pressing. The drained cheeses were immersed in brine containing $15 \%$ salt for $4 \mathrm{~h}$ and placed in PVC boxes for $2 \mathrm{~d}$ at 15 to $17^{\circ} \mathrm{C}$ for preaging. The cheeses were then packed in 1-kg cans, filled with brine (12\% salt), and stored at 4 to $5^{\circ} \mathrm{C}$ for $12 \mathrm{mo}$. The water content of cheese samples was maintained at 57 to $59 \%$ throughout the $12 \mathrm{mo}$ of the experiment. Initially, the mean $\mathrm{pH}$ value of cheese loaves was 5 , and decreased to 4.5 at the end of 12 mo of storage.

\section{Sample Preparation}

At a preestablished time, three cheese cans were opened, and about $100 \mathrm{~g}$ of a representative sample was grated. A 7-g grated sample was added to $40 \mathrm{ml}$ of buffer-acetonitrile mobile phase $(0.5 \% \quad(\mathrm{wt} / \mathrm{vol})$ $\left(\mathrm{NH}_{4}\right)_{2} \mathrm{HPO}_{4}(0.038 M)-0.4 \%$ (vol/vol) acetonitrile $(0.049 \mathrm{M})$, at $\mathrm{pH} 2.24$ with $\left.\mathrm{H}_{3} \mathrm{PO}_{4}\right)$, extracted for $1 \mathrm{~h}$, agitated on a shaker (model 75, Burrell Scientific, Pittsburgh, PA), and centrifuged at $6000 \times g$ for $5 \mathrm{~min}$ according to a modification of the method of Bevilacqua and Califano (1989). The supernatant was filtered once through Whatman \#1 filter paper and twice through a $0.45-\mu \mathrm{m}$ membrane filter (Sartorious SM 11606, Göettingen, Germany), and then used directly for HPLC analysis. Triplicate analyses were performed on all samples.

\section{HPLC Analysis}

A Jasco liquid chromatograph (LC-900 Series, Jasco International Co., Hachioji, Tokyo, Japan) was equipped with a model H-980-01 holder that accepts Rheodyne valves, 7124 injector-fitted with a $20-\mu \mathrm{l}$ sample loop, a Jasco PU-980 solvent delivery system, and a Jasco UV-980 detector. The detector was set at $214 \mathrm{~nm}$.

According to Akalin et al. (1997), operating conditions were: mobile phase, aqueous $0.5 \%$ (wt/vol) $\left(\mathrm{NH}_{4}\right)_{2} \mathrm{HPO}_{4}$ $(0.038 M)-0.2 \%(\mathrm{vol} / \mathrm{vol})$ acetonitrile $(0.049 M)$ adjusted to $\mathrm{pH} 2.24$ with $\mathrm{H}_{3} \mathrm{PO}_{4}$; flow rate $0.3 \mathrm{ml} / \mathrm{min}$; ambient column temperature; and chart speed, $0.8 \mathrm{~cm} /$ min. A reverse-phase Machery Nagel C18 $(120 \times 5 \mathrm{~mm})$ 


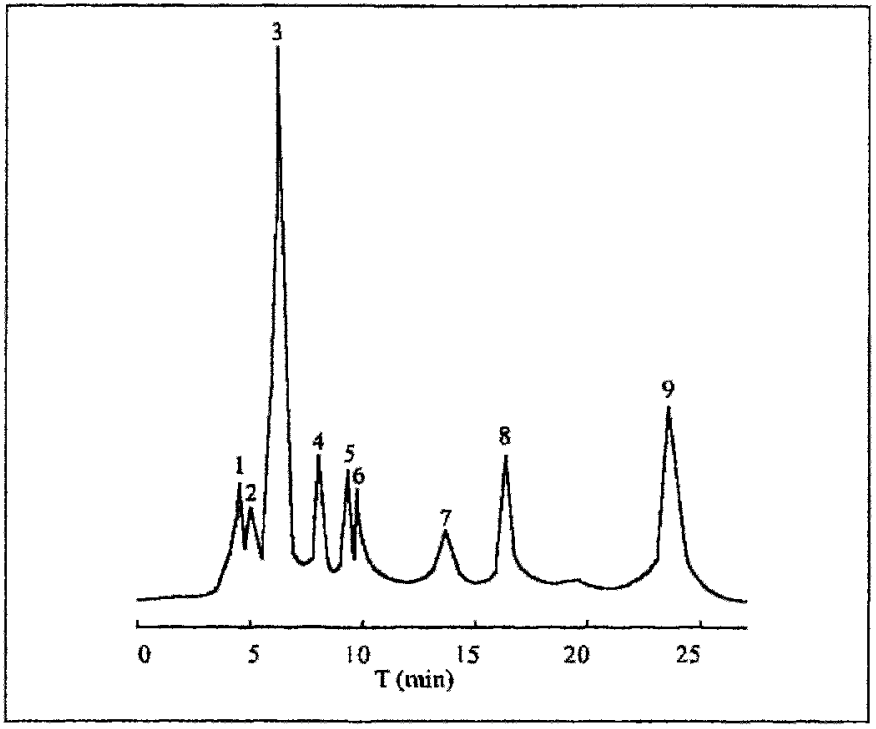

Figure 1. A typical chromatogram of organic acids for pickled White cheese ripened for $9 \mathrm{mo}$. The numbers correspond to the following acids: (1) formic, (2) pyruvic, (3) lactic, (4) acetic, (5) orotic, (6) citric, (7) uric, (8) propionic and (9) butyric. Chromatographic conditions: a reversed-phase $\mathrm{C} 18$ column at ambient temperature, mobile phase of aqueous $0.5 \%(\mathrm{wt} / \mathrm{vol})\left(\mathrm{NH}_{4}\right)_{2} \mathrm{HPO}_{4}(0.038 \mathrm{M})-0.2 \%(\mathrm{vol} /$ vol) acetonitrile $(0.049 \mathrm{M})$ adjusted to $\mathrm{pH} 2.24$ with $\mathrm{H}_{3} \mathrm{PO}_{4}$. UV detection at $214 \mathrm{~nm}$, and $0.3 \mathrm{ml} / \mathrm{min}$ flow rate. (A. S. Akalin, S. Gönç, Y. Akbaş).

column (Machery Nagel, Düren, Germany) was used. The mobile phase was prepared by dissolving analytical-grade $\left(\mathrm{NH}_{4}\right)_{2} \mathrm{HPO}_{4}$ in distilled water, HPLC-grade acetonitrile, and $\mathrm{H}_{3} \mathrm{PO}_{4}$. HPLC-grade reagents were used as standards (Sigma Chemical Co., St. Louis, MO). Solvents were degassed under vacuum. Both solvents and standard solutions were filtered through a 0.45 $\mu \mathrm{m}$ membrane filter (Sartorious SM 11606). Quantita-

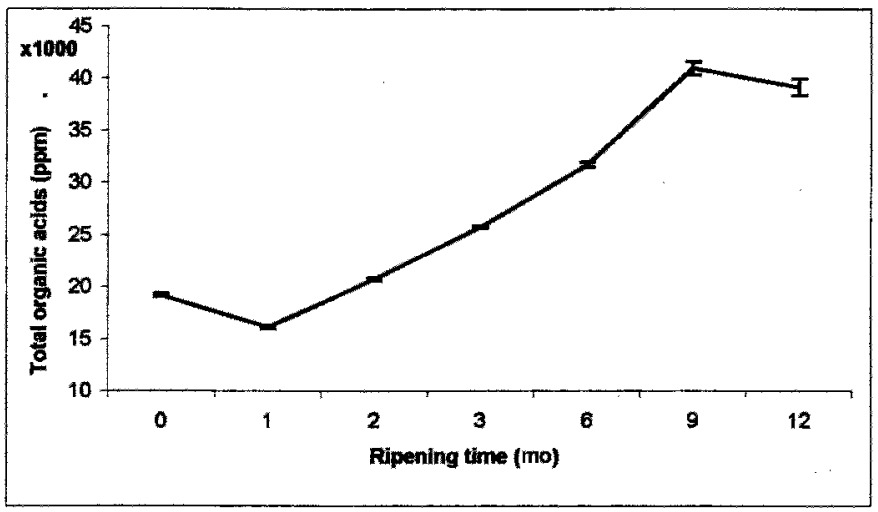

Figure 2. Changes in total organic acids content (ppm) of pickled White cheese during ripening. Bars indicate standard error of the mean (A. S. Akalin, S. Gönç, Y. Akbaş). tion was based on the external standard method (Bevilacqua and Califano, 1989).

Percent recovery was verified with three replicates of 6-mo-old pickled White cheese by adding a known amount of each organic acid standard to the 7-g sample during extraction. The amounts added were roughly $50 \%$ of the actual concentration of the samples. The concentration of each organic acid in the mixture was then determined in a way similar to the sample analysis. All components yielded high-percent recoveries (Table 1).

\section{Statistical Analysis}

Nine organic acids and their age scores at seven agepoints with three replicates $(9 \times 7 \times 3=189$ observations) were considered during statistical analysis.

First, discriminant analysis was applied to the data, which consisted of changes in organic acids during ripening of pickled White cheese. Our aim was to determine whether the classification of the cheese according to ripening time could be solely due to organic acids. Stepwise discriminant analysis was preferred to obtain the list of potential discriminating organic acids to form the discriminant functions. During the stepwise procedure, Wilk' $\Lambda$, which is a multivariate measure of group differences over several variables, was used as a selection criterion to determine the addition or removal of variables in the discriminant function. At each step, an organic acid was either added or deleted from the discriminant function according to the value of Wilk' $\Lambda$. For better visualization, the canonical scores were plotted in discriminant space. Fisher discriminant functions comprising classification coefficients and constants were given for each ripening time to classify the raw data in terms of maturity of the cheese. Canonical discriminant functions, standardized as mean score of zero and within group variance of unit, were also calculated for assessing the relative importance of discriminator variables forming the discriminant function.

Second, stepwise regression analysis was carried out using organic acid concentrations to determine which organic acids were significant predictors for the ripening time. Probabilities of $F$ values to add and remove independent variables into the regression model were 0.05 and 0.10 , respectively.

SPSS for Windows statistical software (SPSS, 1997) was used for all statistical analyses in this study.

\section{RESULTS AND DISCUSSION}

A typical high-performance liquid chromatogram of organic acids for pickled White cheese is shown in Figure 1. 

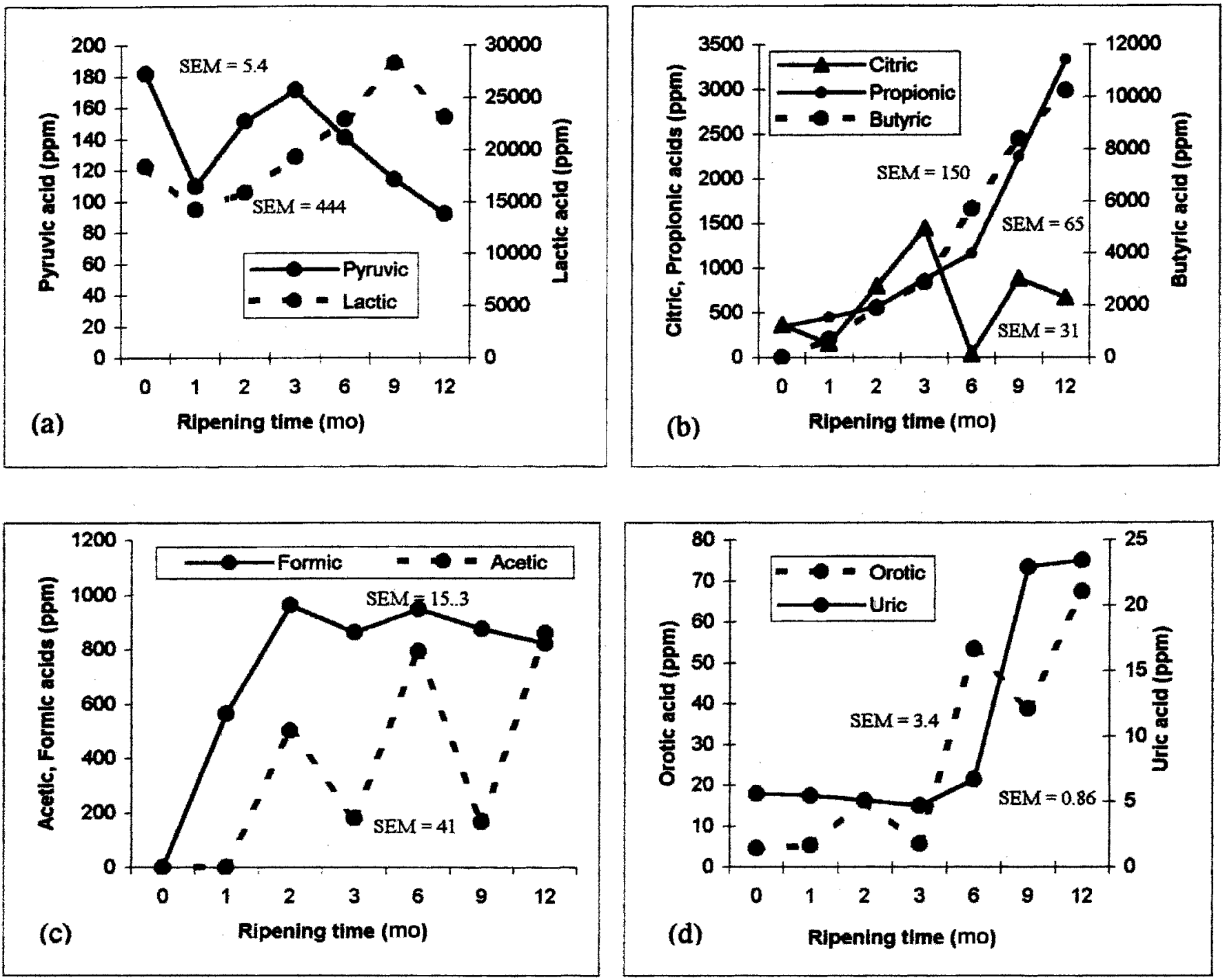

Figure 3. Changes in (a) lactic and pyruvic acids (ppm); (b) propionic, citric, and butyric acid contents (ppm); (c) acetic and formic acid concentration (ppm); (d) orotic and uric acids (ppm) during ripening. SEM indicates standard error of the mean (A. S. Akalin, S. Gönç, Y. Akbaş).

Table 1 shows the retention time (Tr), coefficient of determination $\left(\mathrm{R}^{2}\right)$, and organic acid recovery $(\%)$ of the cheese samples. Excellent linear responses $\left(\mathrm{R}^{2}>0.998\right.$ changing from 0.9982 to 0.9999 ) were found over a wide range of concentrations for all organic acids. The concentration ranges of organic acid standards were 10 to $70 \mu \mathrm{g} / \mathrm{ml}$ for orotic and uric acids, 1000 to $5000 \mu \mathrm{g} / \mathrm{ml}$ for citric, 50 to $1000 \mu \mathrm{g} / \mathrm{ml}$ for formic and acetic, 10 to $200 \mu \mathrm{g} / \mathrm{ml}$ for pyruvic, 1000 to $20,000 \mu \mathrm{g} / \mathrm{ml}$ for lactic, 100 to $1500 \mu \mathrm{g} / \mathrm{ml}$ for propionic, and 100 to $10,000 \mu \mathrm{g} / \mathrm{ml}$ for butyric acid. Efficiency of the extraction procedure, measured by adding to a White cheese sample known amounts of standard solutions containing the acids, ranged from 86.3 to $98.7 \%$ (Table 1). High-recovery ratios were in agreement with other authors (Marsili,
1985; St-Gelais et al., 1991). Using the same extraction method, Lues et al. (1998) reported recovery rates ranging from 86.4 (butyric acid) to 94.3 (propionic acid) for the same nine organic acids in Cheddar cheese samples.

Average concentrations of total organic acids in cheese samples showed a marked increase between mo 1 and 9 of ripening (Figure 2).

Lactic acid concentration also presented a similar pattern of change, presenting a maximum plateau in the ninth month. Initially, it accounted for about $95 \%$ of the total organic acid content. The primary purpose of a dairy starter culture is to produce lactic acid from lactose at a high rate in the early stages, the lactic acid acting to inhibit contaminants (i.e., coliforms; Scott, 1986). Formation of lactic acid is essential for proper 


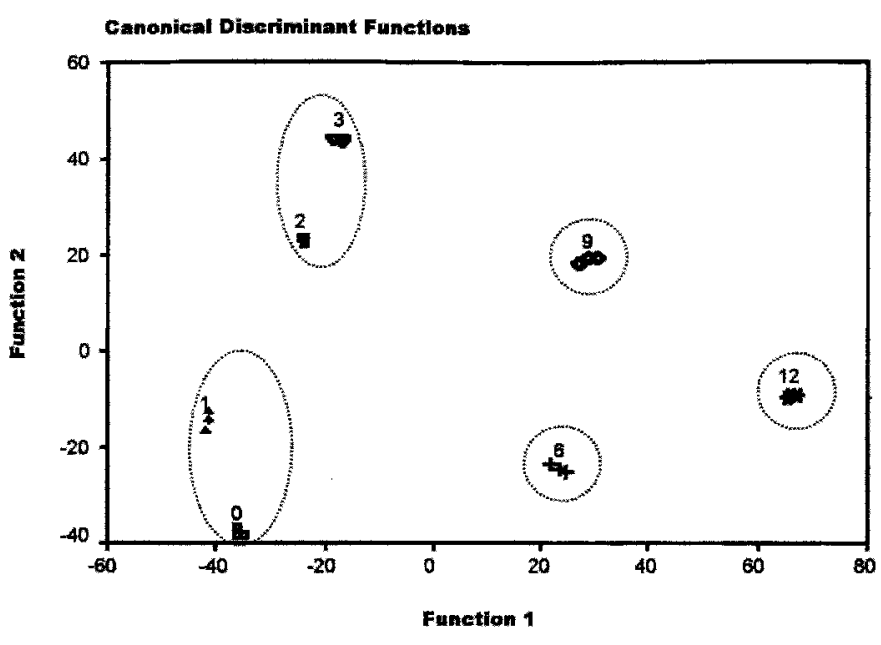

Figure 4. Canonical plot of 21 pickled White cheese samples. Numbers and symbols indicate ripening time and the location of the samples, respectively: $0, \square$ for $0 \mathrm{mo} ; 1, \mathbf{\Delta}$ for $1 \mathrm{mo} ; 2, \times$ for $2 \mathrm{mo} ; 3$, $\nabla$ for $3 \mathrm{mo} ; 6$, + for $6 \mathrm{mo} ; 9$, $\diamond$ for $9 \mathrm{mo} ; 12$, * for $12 \mathrm{mo}$ (A. S. Akalin, S. Gönç, Y. Akbaş).

manufacture, flavor development, normal ripening, and good keeping quality (Wong, 1974). After aging for 2 mo, lactic acid represented $76 \%$ of the total acids and $69 \%$ and $60 \%$ after ripening for 9 and 12 mo, respectively (Figure 3a).

Butyric and propionic acid concentrations increased as ripening progressed, although at different rates. A rapid increase specifically in butyric acid concentration was responsible for higher organic acid content especially for the last several months. While butyric acid represented $0 \%$ of the initial total organic acid concentration, it accounted for 18,20 , and $27 \%$ of the total organic acid content after ripening for 6,9 , and $12 \mathrm{mo}$, respectively (Figure 3b). Similar results were obtained for Cheddar, Swiss, Reggianito, and Port Salut Argentino cheeses for lactic, propionic, and/or butyric acids (St-Gelais et al., 1991; Bevilacqua and Califano, 1992; Fedio et al., 1994; Lombardi et al., 1994).
The presence of free fatty acids of short-chain like acetic, propionic, and butyric acids is mainly related to the intensity of bacterial fermentation that took place during ripening. Butyric and propionic acid fermentations were the result of the lipolytic and especially proteolytic activity of starters and an abundant secondary microflora (Esponda et al., 1983). If the milk fat globule membrane was damaged during cheese making, lipolysis and release of fatty acids such as butyric acid would be facilitated (Caboni et al., 1990).

Formic acid was formed during the first month of ripening, then increased in the second month and remained fairly constant thereafter (Figure 3c). The initial increase in formic acid might be explained by the presence of Streptococcus salivarius ssp. thermophilus, which produces formic acid from lactose (Thomas, 1985). Bevilacqua and Califano (1992), Lombardi et al. (1994), and Califano and Bevilacqua (1999) also observed a similar trend for formic acid in the beginning of ripening of Port Salut Argentino, Reggianito, and low-moisture Mozzarella cheese, respectively.

Acetic acid was produced in the second month and showed irregular changes thereafter, with a maximum content around $12 \mathrm{mo}$ of aging and a minimum at 9 mo (Figure 3c).

Citric acid also showed irregular changes with a slight tendency to decrease during ripening (Figure 3b), similar to findings of Lombardi et al. (1994) for Reggianito cheese. This decrease might be explained by citrate metabolism. Citrate is involved in the Krebs or citric acid cycle, where it acts both as substrate and product. Citrate can be used as substrate by the starter to produce pyruvic and acetic acids (Adda et al., 1982). Lactococcus lactis ssp. cremoris may utilize citrate.

Uric acid content remained fairly constant between the first and sixth months, rising sharply thereafter. Both uric and orotic acids concentrations were found to be highest at the end of ripening (Figure $3 \mathrm{~d}$ ).

Pyruvic acid content decreased during aging, except between the first and third months (Figure 3a). Py-

Table 2. Classification function coefficients (Fisher's linear discriminant functions) for each ripening time.

\begin{tabular}{lrrrrrrrr}
\hline & \multicolumn{7}{c}{ Time (mo) } \\
\cline { 2 - 8 } & \multicolumn{1}{c}{1} & & 2 & 3 & & 6 & 9 & 12 \\
\hline Formic & 1.169 & 3.195 & 5.290 & 5.989 & 1.853 & 4.149 & 1.922 \\
Lactic & 0.326 & 0.251 & 0.280 & 0.331 & 0.367 & 0.464 & 0.323 \\
Acetic & -0.291 & -0.345 & 0.663 & -0.167 & 1.306 & -0.201 & 1.615 \\
Orotic & 0.431 & -12.997 & -22.826 & -21.344 & 12.551 & 3.808 & 20.916 \\
Citric & 0.853 & 1.372 & 2.797 & 3.754 & 1.215 & 2.785 & 1.981 \\
Uric & 63.446 & 86.554 & 104.257 & 102.095 & 25.458 & 67.881 & -19.374 \\
Propionic & -0.575 & -0.350 & -0.165 & -0.066 & -0.011 & 0.158 & 1.045 \\
Butyric & -0.140 & -0.232 & -0.273 & -0.267 & 0.129 & 0.012 & 0.327 \\
(Constant) & -3221 & -2829 & -5816 & -8236 & -6390 & $-10,659$ & -9762 \\
\hline
\end{tabular}


Table 3. Standardized canonical discriminant function coefficients.

\begin{tabular}{|c|c|c|c|c|c|c|}
\hline & \multicolumn{6}{|c|}{ Functions } \\
\hline & 1 & 2 & 3 & 4 & 5 & 6 \\
\hline Formic & 0.333 & 1.689 & 0.189 & 0.413 & 0.693 & 0.125 \\
\hline Lactic & -0.499 & 0.201 & -1.781 & 1.064 & -0.321 & 0.502 \\
\hline Acetic & -0.376 & -0.132 & 0.772 & 0.530 & -0.413 & 0.622 \\
\hline Orotic & -2.769 & -2.758 & -1.257 & -0.428 & -0.887 & -2.466 \\
\hline Citric & -0.092 & 1.540 & -0.055 & -0.228 & -0.630 & -0.108 \\
\hline Uric & 1.714 & 1.479 & -0.745 & 1.095 & 1.184 & 2.371 \\
\hline Propionic & -0.647 & 0.147 & 0.446 & -0.795 & 0.196 & 0.045 \\
\hline Butyric & -1.545 & -0.871 & 0.104 & -0.246 & -0.206 & -1.031 \\
\hline
\end{tabular}

ruvate is readily formed through the glycolytic pathway, but it also acts as substrate of several metabolic reactions such as the formation of formic acid, ethanol, and diacetyl, acetoin, and 2,3-butylene glycol (Marth, 1974)

By stepwise discriminant analysis, eight organic acids (formic, lactic, acetic, orotic, citric, uric, propionic, and butryric acids) were selected, but pyruvic was omitted by the program to be the most effective for discrimination of ripening time. Since six discriminant functions explained the total variances among discriminating variables, six canonical discriminant functions were used in the analysis; $100 \%$ of the variation among ripening time groups was accounted by these discriminating variables. Most of the variation is explained by the first three functions; $56 \%$ of the variance was explained by the first discriminant function, while second and third discriminant functions explained 29.9 and $9 \%$ of the variance, respectively.

All ripening time groups were discriminated separately by the program. There was no difference between the actual group of cheese and assigned group of cheese by discriminant analysis.

Classification functions were given for each ripening time in Table 2. Observations are assigned to the groups with the largest classification score. Discrimination score of any pickled White cheese sample in which ripening time and characteristics were unknown can be calculated by substituting acid contents, and that sample can be assigned to the ripening time group with the largest discriminant score.

Standardized canonical discriminant functions for assessing the relative importance of discriminator variables forming the discriminant function are given in Table 3 . The greater the standardized coefficient, the greater the relative importance of variables. For example, the relative importance of orotic, uric, and butyric acids was greater than that of the other organic acids from function 1 in Table 3.

Although seven groups were discriminated by the program, Figure 4 shows that five subsets may be con- sidered according to their acid contents: 1) young or fresh cheeses, between 0 and first month, characterized by a decrease in pyruvic, lactic, and citric acid contents and by an increase in propionic, butyric, and formic acid concentrations; 2) middle-aged cheeses, 2 to $3 \mathrm{mo}$, which correspond to a period in which pyruvic, lactic, citric, propionic, and butyric acid concentrations increased and acetic, formic, orotic, and uric acids decreased; 3) old cheeses (6 mo) characterized for a high lactic, propionic, butyric, formic, acetic, orotic, and extremely low citric acid contents; 4) and 5) long-ripened cheeses, 9 and 12 mo, respectively, samples of high total organic acid concentration, mainly because of the increase in first lactic, second butyric, and propionic acid contents for $9 \mathrm{mo}$, and further increase in butyric and propionic acids as well as relatively high concentration of lactic acid contents for 12 mo.

Butyric, propionic, orotic, and formic acid concentrations were found to be significant predictors of ripening time (T) by stepwise regression analysis. Estimated regression equation is:

$$
\begin{gathered}
\mathrm{T}=-0.475+6.472 \times 10^{-4} \text { butyric }+1.368 \\
\times 10^{-3} \text { propionic }+1.520 \times 10^{-2} \text { orotic } \\
+3.807 \times 10^{-4} \text { formic }
\end{gathered}
$$

The adjusted coefficient of determination and multiple correlation coefficient were 0.998 and 0.999 , respectively.

\section{ACKNOWLEDGMENTS}

The authors thank Özer Kinik and Kadir Damci for their technical assistance. This work was supported by Univ. of the Aegean, Faculty of Agriculture, Research Fund Council.

\section{REFERENCES}

Adda, J., J. C. Gripon, and L. Vassal. 1982. The chemistry of flavor and texture generation in cheese. Food Chem. 9:115-129. 
Akalin, A. S., Ö. Kinik, and S. Gönç. 1997. Determination of organic acids in commercial cheeses by high-performance liquid chromatography. Milchwissenschaft 52:260-262.

Alonso, L., M. Ramos, P. J. Martin-Alvarez, and M. Juárez. 1987. Application of stepwise discriminant analysis to parameters for characterizing frozen Cabrales cheese. J. Dairy Sci. 70:905-908.

Bevilacqua, A. E., and A. N. Califano. 1989. Determination of organic acids in dairy products by high-performance liquid chromatography. J. Food Sci. 54:1076-1079.

Bevilacqua, A. E., and A. N. Califano. 1992. Changes in organic acids during ripening of Port Salut Argentino cheese. Food Chem. 43:345-349.

Caboni, M. F., M. Zannoni, and G. Lercker. 1990. Fat lipolysis in Parmigiano-Reggiano cheese. Sci. Tecnica Lattiero-Casearia, 41(Suppl.):289-297.

Califano, A. N., and A. E. Bevilacqua. 1999. Freezing low-moisture Mozzarella cheese: changes in organic acid content. Food Chem. 64:193-198.

Esponda, R. A., M. A. Tessi, I. S. Comini, S. M. Terenzani, S. G. Porta, M. C. Silva, and M. A. Moguilevsky. 1983. Microbiologia de queso quertirolo: influencia de la materia prima y de las condiciones de fabricación en el contenido microbiano inicial. Aliment Latinoam. 129:65-69.

Farkye, N. Y., and P. F. Fox. 1990. Objective indices of cheese ripening. Trends Food Sci. Technol. 1:37-40.

Fedio, W. M., L. Ozimek, and F. H. Wolfe. 1994. Gas production during the storage of Swiss cheese. Milchwissenschaft 49:3-8.

Hough, G., A. N. Califano, N. C. Bertola, A. E. Bevilacqua, E. Martinez, M. J. Vega, and N. E. Zaritzky. 1996. Partial least square correlations between sensory and instrumental measurements of flavor and texture for Reggianito grating cheese. Food Qual. Preference 7:47-53.

Law, B. 1984. Flavor development in cheeses. Pages 187-208 in Advances in the Microbiology and Biochemistry of Cheese and Fermented Milk. F. L. Davies and B. Law, ed. Elsevier Sci., Inc., New York, NY.

Lombardi, A. M., A. E. Bevilacqua, and A. N. Califano. 1994. Variation in organic acids content during ripening of Reggianito cheese in air-tight sealed bags. Food Chem. 51:221-226.
Lues, J. F. R., and W. C. Botha. 1998. Relationship amongst South African processed, young, and matured Cheddar cheese pertaining to organic acid content and non-starter population. Food Res. Int. 31:449-457.

Lues, J. F. R., W. C. Botha, and E. J. Smit. 1998. Ion-exchange HPLC analysis of a broad spectrum of organic acids from matured Cheddar cheese and assessment of extraction methods. Food Res. Int. 31:441-447.

Marsili, R. T. 1985. Monitoring chemical changes in Cheddar cheese during aging by high-performance liquid chromatography and gas chromatography techniques. J. Dairy Sci. 68:3155-3161.

Marth, E. H. 1974. Fermentations. Pages 772-872 in Fundamentals of Dairy Chemistry. B. H. Webb, A. H. Johnson, and J. A. Alford, eds. AVI Publishing Co., Inc., Westport, CT.

Mohler Smith, A., and S. Nakai. 1990. Classification of cheese varieties by multivariate analysis of HPLC profiles. Can. Inst. Food Sci. Technol. J. 23:53-58.

Panari, G. 1986. HPLC of organic acids: an approach to cheese analysis. Milchwissenschaft 41:214-216.

Pham, A., and S. Nakai. 1983. Application of stepwise discriminant anlysis to high-pressure liquid chromatography profiles of water extract for judging ripening of Cheddar cheese. J. Dairy Sci. 67:1390-1396.

St-Gelais, D., G. Doyon, J. R. Rolland, and J. Goulet. 1991. Sugar and organic acid concentrations during ripening of Cheddar cheese-like products. Milchwissenschaft 46:288-291.

Scott, R. 1986. Cheesemaking Practice. 2nd ed. Elsevier Sci., Inc., London, UK.

Seitz, E. W. 1990. Microbial- and enzyme-induced flavors in dairy foods. J. Dairy Sci. 73:3664-3691.

SPSS, 1997. SPSS for Windows Release 8.0. SPSS, Inc., Chicago, IL.

Thomas, T. D. 1985. Role of lactic acid bacteria and their improvement for production of better fermented animal products. N.Z. J. Dairy Sci. Technol. 20:1-10.

Urbach, G. 1993. Relations between cheese flavor and chemical composition. Int. Dairy J. 3:389-422.

Wong, N. P. 1974. Cheese Chemistry. Pages 719-752 in Fundamentals of Dairy Chemistry. B. H. Webb, A. H. Johnson, and J. Alford, ed. AVI Publishing Co., Inc., Westport, CT. 